\title{
Fabrication of Anisotropic Cu Ferrite-Polymer Core-Shell Nanoparticles for Photodynamic Ablation of Cervical Cancer Cells
}

\author{
Shuo-Hsiu Kuo ${ }^{1}$, Po-Ting Wu ${ }^{1}$, Jing-Yin Huang ${ }^{2}$, Chin-Pao Chiu ${ }^{2}$, Jiashing Yu ${ }^{1, * \mathbb{C}}$ and \\ Mei-Yi Liao ${ }^{2, *}$ \\ 1 Department of Chemical Engineering, National Taiwan University, Taipei 10617, Taiwan; \\ b05504084@ntu.edu.tw (S.-H.K.); r05524112@ntu.edu.tw (P.-T.W.) \\ 2 Department of Applied Chemistry, National Pingtung University, Pingtung 90003, Taiwan; \\ mingsoo77@gmail.com (J.-Y.H.); snack95064@gmail.com (C.-P.C.) \\ * Correspondence: jiayu@ntu.edu.tw (J.Y.); myliao@mail.nptu.edu.tw (M.-Y.L.); Tel.: +886-2-3366-9477 (J.Y.); \\ +886-8-766-3800 (ext. 33261) (M.-Y.L.)
}

Received: 2 November 2020; Accepted: 2 December 2020; Published: 4 December 2020

\begin{abstract}
In this work we developed methylene blue-immobilized copper-iron nanoparticles (MB-CuFe NPs) through a facile one-step hydrothermal reaction to achieve a better phototherapeutic effect. The $\mathrm{Fe} / \mathrm{Cu}$ ratio of the $\mathrm{CuFe} \mathrm{NPs}$ was controllable by merely changing the loading amount of iron precursor concentration. The CuFe NPs could serve as a Fenton catalyst to convert hydrogen peroxide $\left(\mathrm{H}_{2} \mathrm{O}_{2}\right)$ into reactive oxygen species (ROS), while the superparamagnetic properties also suggest magnetic resonance imaging (MRI) potential. Furthermore, the Food and Drug Administration (FDA)-approved MB photosensitizer could strongly adsorb onto the surface of CuFe NPs to facilitate the drug delivery into cells and improve the photodynamic therapy at $660 \mathrm{~nm}$ via significant generation of singlet oxygen species, leading to enhanced cancer cell-damaging efficacy. An MTT (thiazolyl blue tetrazolium bromide) assay proved the low cytotoxicity of the CuFe NPs to cervical cancer cells (HeLa cells), namely above $80 \%$ at 25 ppm of the sample dose. A slight dissolution of $\mathrm{Cu}$ and $\mathrm{Fe}$ ions from the CuFe NPs in an acidic environment was obtained, providing direct evidence for $\mathrm{CuFe} \mathrm{NPs}$ being degradable without the risk of long-term retention in the body. Moreover, the tremendous photo-to-thermal conversion of CuFe NPs was examined, which might be combined with photodynamic therapy (PDT) for promising development in the depletion of cancer cells after a single pulse of deep-red light irradiation at high laser power.
\end{abstract}

Keywords: bimetallic nanoparticles; superparamagnetic nanoparticles; Fenton reaction; reactive oxygen species; cancer treatment; photodynamic therapy

\section{Introduction}

Nanoparticles (NPs) have become a burgeoning alternative in biomedical use and cancer treatment because their small size allows them to exhibit an enhanced optical signal for immunosensing applications, multiple theranostics functions, and long retention time in the human body [1-7]. Metallic nanoparticles have drawn extensive attention and provided a new point of view on unresolved problems. The physicochemical properties of the high surface-volume ratio, localized surface plasmon resonance (LSPR) effect, and small-size-induced internalization empower the nanoparticles to approach the abnormal tissues and passively accumulate therein, improving tumor treatment efficacy [8-12].

Previous research has developed one-step hydrothermal synthesis to produce various metalcore-polymer-shell nanoparticles, including Au@polymer NPs, $\mathrm{Cu} @$ polymer NPs, and $\mathrm{Fe}_{3} \mathrm{O}_{4} @$ polymer NPs [13]. The applications of Au@polymer NPs and $\mathrm{Cu} @ \mathrm{Cu}_{2} \mathrm{O} @$ polymer NPs to cancer treatment were 
also investigated with in vitro and in vivo experiments [14,15]. Copper nanoparticles (CuNPs) have been widely studied as a photothermal agent for near-infrared (NIR) absorption via the plasmonic effect [15-20]. When the temperature exceeds $48{ }^{\circ} \mathrm{C}$, cells are irreversibly damaged and undergo apoptosis processes [21,22]. In addition, the better biodegradability of $\mathrm{Cu}$-based nanomaterials compared to noble metals frequently used in cancer therapy makes integrating $\mathrm{Cu}$ element into the nanostructures less likely to accumulate in the living body [23-27]. On the other hand, iron-related nanoparticles are also popular candidates in biomedical applications, for example, as an effective magnetic resonance imaging (MRI) agent, bioimaging, and magnetic separation [28-34]. Moreover, Fe ions released from iron-related nanoparticles can enhance chemodynamic therapy by $\mathrm{H}_{2} \mathrm{O}_{2}$ disproportion and generate reactive oxygen species (ROS), even producing oxygen in a high $\mathrm{H}_{2} \mathrm{O}_{2}$ environment by Fenton reactions, a common and crucial physiological process regulating ROS levels [35-39]. Since cancer cells reportedly contain high levels of $\mathrm{H}_{2} \mathrm{O}_{2}$, an increase in ROS generation can be specific to cancer tissues [40,41]. In addition, Mazuel et al. found intracellular biodegradability of Fe-based NPs by examining the decrease in the magnetism and particle solid volume after 27 days of treatment in the tumor site [42].

Therefore, the combination of CuNPs and FeNPs with light exposure has become well-known. Liu et al. developed a $\mathrm{CuFe}_{2} \mathrm{O}_{4}$ nanoparticle synthesis with bovine serum albumin, proved the enhanced ROS generation ability, and examined the ability in vitro and in vivo of effective photothermal therapy (PTT) and MRI [43]. Guo et al. designed a biocompatible sub-10 $\mathrm{nm} \mathrm{Cu}_{5} \mathrm{FeS}_{4}$ cube for MRI and PTT and experimented with human umbilical vein endothelial cell (HUVEC) [44]. Ding et al. verified the apoptotic cell death pathway triggered by $\mathrm{CuFeS}_{2}$ nanoplates with irradiation [45]. Lin et al. presented a paradigm of the facile phase transfer of hydrophobic $\mathrm{Fe}_{3} \mathrm{O}_{4} @ \mathrm{Cu}_{2-\mathrm{x}} \mathrm{S}$ theranostics for both MRI and PTT [46]. Comparison of the recent research studies is shown in Table 1. However, nanoparticle-mediated photodynamic therapy showed a smaller side effect to normal tissue compared with PTT treatment because the threshold to trigger photodynamic therapy (PDT) received a much lower power density threshold of laser light $[3,11,12,47]$. The biomedical applications of CuNP-doped copper ferrite nanoparticles to carry phototherapeutic agents and improve phototherapy are not yet well explored.

Table 1. Comparison of relevant works on copper and iron nanocomposites.

\begin{tabular}{|c|c|c|c|c|c|c|}
\hline Author & Material & Application & PTT & MRI & Degradability & $\begin{array}{c}\text { ROS } \\
\text { Enhancement }\end{array}$ \\
\hline Liu et al. & $\mathrm{CuFe}_{2} \mathrm{O}_{4}$ & $\begin{array}{l}\text { Cancer } \\
\text { therapy }\end{array}$ & $\checkmark$ & $\checkmark$ & & $\checkmark$ \\
\hline Wang et al. & $\mathrm{Cu}_{5} \mathrm{FeS}_{4}$ & $\begin{array}{l}\text { Cancer } \\
\text { therapy }\end{array}$ & $\checkmark$ & $\checkmark$ & & \\
\hline Tai et al. & $\mathrm{Cu} @ \mathrm{Cu}_{2} \mathrm{O}$ & $\begin{array}{l}\text { Cancer } \\
\text { therapy }\end{array}$ & $\checkmark$ & & $\checkmark$ & $\checkmark$ \\
\hline Kao et al. & $\mathrm{Fe}_{3} \mathrm{O}_{4}$ & $\begin{array}{c}\text { Atherosclerosis } \\
\text { diagnosis }\end{array}$ & & $\checkmark$ & & \\
\hline Mazuel et al. & $\gamma-\mathrm{Fe}_{2} \mathrm{O}_{3}$ & $\begin{array}{l}\text { Intracellular } \\
\text { biodegradation }\end{array}$ & & $\checkmark$ & $\checkmark$ & \\
\hline Lin et al. & $\mathrm{Fe}_{3} \mathrm{O}_{4} @ \mathrm{Cu}_{2-\mathrm{x}} \mathrm{S}$ & $\begin{array}{l}\text { MRI, cancer } \\
\text { therapy }\end{array}$ & $\checkmark$ & $\checkmark$ & & \\
\hline
\end{tabular}

To boost the therapeutic effect, simultaneous PDT/PTT therapy has recently burgeoned [48-50]. Methylene blue (MB) is susceptible to light and has become one of the most prevailing photosensitizers used in conjugation with nanoparticles for cancer treatment [14,51,52]. Because of the high quantum yield of singlet oxygen species to enhance the photolysis of several cancer cell lines, MB has been loaded or encapsulated in various therapeutic nanoplatforms [53-55]. More importantly, MB is a drug approved by the U.S. Food and Drug Administration (FDA), supporting the feasibility of in vivo or human tests. Accordingly, it is natural to take these characteristics into account and devise 
an MB@NPs composite, endowing the conjoined nanoplatform with versatile advantages to attain improved performance in tumor destruction.

In this work, a copper-iron dual-metal nanocomposite (i.e., copper ferrite nanocrystal) immobilized with methylene blue for photodynamic therapy was proposed. The facile poly(styrene-alt-maleic acid) sodium salt solution (PSMA)-assisted synthesis method promised practicability in mass production of copper ferrite@PSMA nanocrystal. Due to the loaded Fe forming copper ferrite nanocrystal, the Cu-based nanoagent could trigger the ROS via Fenton reactions in the presence of an $\mathrm{H}_{2} \mathrm{O}_{2}$ environment. The loaded MB photosensitizer on the surface of copper ferrite nanocrystal could enhance singlet oxygen production when exposed to light at a deep red wavelength. The results substantiated this state-of-the-art copper ferrite@PSMA@MB nanocrystal design as promising for the internalization of cervical cancer cells (HeLa) and enhancing ROS generation, providing a new direction for ROS-combined phototherapy of HeLa cancer cells. Moreover, a trace of metallic $\mathrm{Cu}$ nanocrystals was hybridized with the copper ferrite@PSMA nanocrystal to achieve a surface plasmon resonance (SPR) band at $\sim 600 \mathrm{~nm}$. The $\mathrm{Cu}$ metal compartment might serve as a highly efficient light-absorbent material conducive to hyperthermia via light-to-thermal conversion in tumor sites, making it a possible candidate for photothermal therapy.

\section{Materials and Methods}

\subsection{Materials}

Copper(II) chloride dehydrate $\left(\mathrm{CuCl}_{2} \cdot 2 \mathrm{H}_{2} \mathrm{O}\right)$, hydrochloric acid $(\mathrm{HCl}, 37 \%)$, nitric acid $\left(\mathrm{HNO}_{3}\right.$, $65 \%$ ), and Dulbecco's modified Eagle's medium-high glucose (DMEM/HG) were purchased from Thermo Fisher Scientific (Massachusetts, USA). Iron(II) chloride anhydrous $\left(\mathrm{FeCl}_{2}, 99.5 \%\right)$, methylene blue $\left(\mathrm{C}_{16} \mathrm{H}_{18} \mathrm{ClN}_{3}\right)$ and thiazolyl blue tetrazolium bromide (MTT) were from Alfa Aesar (Massachusetts, USA). Hydrazine hydrate $\left(\mathrm{N}_{2} \mathrm{H}_{4} \cdot \mathrm{H}_{2} \mathrm{O}\right)$ and sodium pyruvate $\left(\mathrm{C}_{3} \mathrm{H}_{3} \mathrm{NaO}_{3} \mathrm{~S} \cdot \times \mathrm{H}_{2} \mathrm{O}\right)$ were from Acros Organics (Morris Plains, NJ, USA). poly(styrene-alt-maleic acid) sodium salt solution (PSMA), hydrogen peroxide $\left(\mathrm{H}_{2} \mathrm{O}_{2}\right), 2^{\prime}, 7^{\prime}$-dichlorofluorescein diacetate (DCFH-DA), sodium bicarbonate $\left(\mathrm{NaHCO}_{3}\right)$, trypan blue $(0.4 \%)$, imidazole, $\mathrm{N}, \mathrm{N}$-dimethyl-4-nitrosoaniline (RNO), $\mathrm{N}$-(3-dimethylaminopropyl)-N'-ethylcarbodiimide hydrochloride (EDC), N-hydroxysuccinimide (NHS), and folic acid $\left(\mathrm{C}_{19} \mathrm{H}_{19} \mathrm{~N}_{7} \mathrm{O}_{6}\right)$ were purchased from Sigma-Aldrich (St. Louis, MO, USA). Fetal bovine serum (FBS), trypsin-ethylenediaminetetraacetic acid(trypsin-EDTA, 0.25\%) and antibiotic-antimycotic (penicillin/streptomycin/amphotericin B) were from Biological Industries (Cromwell, CT, USA). Dimethyl sulfoxide was from Scharlau (Barcelona, Spain).

\subsection{Methods}

\subsubsection{CuFe Nanoparticles (NPs) Synthesis}

For each group, all of the reactants in Table S1 were added into a $23 \mathrm{~mL}$ Teflon-lined hydrothermal synthesis autoclave reactor (TM-326, TOMIN, New Taipei, Taiwan). Note that $\mathrm{N}_{2} \mathrm{H}_{4}$ was the last added chemical due to its high reactivity. Then the reactors were heated at $158^{\circ} \mathrm{C}$ for $6 \mathrm{~h}$. After heating, the reactors were placed at room temperature to cool down. The product solution was centrifuged at $11,000 \times g$ for $10 \mathrm{~min}$, and the supernatant was then removed. The CuFe NP precipitate was resuspended in $1 \mathrm{~mL}$ deionized water (DI water) using an ultrasonic oscillator (DC150, Delta ${ }^{\circledR}$, TM-326, TOMIN, New Taipei, Taiwan). The washing process was repeated three times. Afterward, the nanoparticle solution was centrifuged at a low speed $(250 \times g)$ to remove large aggregations.

\subsubsection{Quantification of Copper and Iron Concentration}

The polymer shell and the metal core had to be broken down to quantify metal concentration. $100 \mu \mathrm{L}$ of the nanoparticle solution was first mixed with $225 \mu \mathrm{L}$ of $12 \mathrm{M} \mathrm{HCl}$ and $225 \mu \mathrm{L}$ of $16 \mathrm{M}$ $\mathrm{HNO}_{3}$ to dissolve metal, followed by addition of $1800 \mu \mathrm{L}$ of $4.5 \mathrm{M} \mathrm{NaOH}$ to break down the polymer 
shell. Then, $300 \mu \mathrm{L}$ of $12 \mathrm{M} \mathrm{HCl}$ and $1350 \mu \mathrm{L}$ of DI water were added to keep the solution acidic. Finally, the concentration of iron and copper in the nanoparticles was quantified by atomic absorption microscopy (AA; AAnalyst200, Perkin Elmer, Waltham, MA, USA).

\subsubsection{Metal Ratio and Optical Properties}

The metal ratio was quantified by AA. The optical properties were characterized by an ultraviolet (UV)-visible spectrometer (CARY 300nc, Agilent, Santa Clara, CA, USA). The scanning region was from 800 to $200 \mathrm{~nm}$, where the speed was $10 \mathrm{~nm} / \mathrm{s}$ and the UV-visible slit was switched at the wavelength of $350 \mathrm{~nm}$.

\subsubsection{Catalytic Properties of CuFe NPs}

To check if $\mathrm{CuFe}$ NPs were able to catalyze $\mathrm{H}_{2} \mathrm{O}_{2}$ degradation and accelerate reactive oxygen species (ROS) generation, the DCFH-DA assay was applied. The existence of ROS could turn DCFH-DA into dichlorofluorescein (DCF), which exhibited fluorescence. $100 \mu \mathrm{L}$ of the solution that consisted of $5 \mathrm{ppm}$ of iron, $2.5 \mu \mathrm{M}$ of DCFH-DA, and $500 \mu \mathrm{M}$ of $\mathrm{H}_{2} \mathrm{O}_{2}$ was placed in a 96-well plate and reacted for $16 \mathrm{~h}$. The fluorescence intensity was quantified by a multi-mode microplate reader (SpectraMax i3x, Molecular Devices, San Jose, CA, USA) at the excitation wavelength of $488 \mathrm{~nm}$ and the emission wavelength of $525 \mathrm{~nm}$.

\subsubsection{Degradability Test}

CuFe NPs were dispersed in DI water, phosphate-buffered saline (PBS, $\mathrm{pH}=7.4$ ), acidic PBS $(\mathrm{pH}=4.5)$, culture medium, and $0.5 \% \mathrm{H}_{2} \mathrm{O}_{2}$ under room temperature, respectively. At different time intervals, the $\mathrm{CuFe}$ NPs solutions were centrifuged at $11,000 \times \mathrm{g}$ for $10 \mathrm{~min}$ and then the supernatant was removed. The concentration of iron and copper was quantified by AA.

\subsubsection{Structures, Compositions, Size Distribution and Zeta Potential}

Transmission electron microscopy (TEM; JEM-2000EXII, JOEL, Tokyo, Japan) was used to determine the structure of the CuFe NPs. To characterize the composition, CuFe NPs solution was dropped on a slide glass and then vacuumed to remove water and form an opaque film. The thin film was characterized by X-ray thin-film diffractometer (XRD; X'PERT, Philips, Amsterdam, the Netherlands) at the scan speed of $0.100^{\circ} / \mathrm{s}$ and $0.2 \mathrm{~s} / \mathrm{step}$, where $2 \theta$ was from $20^{\circ}$ to $80^{\circ}$. The size distribution and zeta potential were determined by dynamic light scattering (DLS; Zetasizer Nano, Malvern, UK).

\subsubsection{Magnetic Attraction}

The magnetic attraction ability was simply observed by recording the solution under the magnetic field for $15 \mathrm{~min}$. The observations at 0,5,15 min, and the side views after $15 \mathrm{~min}$ interaction were sorted out.

\subsubsection{Induced Magnetic Flux Density (B)-Magnetizing Force (H) Hysteresis Loop}

The CuFe NPs solutions were frozen at $-20{ }^{\circ} \mathrm{C}$ overnight, followed by lyophilization to remove water. The hysteresis loop of the CuFe NPs was measured in \pm 2 Tesla at $310 \mathrm{~K}$ with a superconducting interference magnetometer (MPMS3, Quantum Design, San Diego, CA, USA).

\subsubsection{Cell Culture}

In this research, HeLa cells were applied in all in vitro experiments, and the cells were obtained from the Department of Plant Pathology and Microbiology, National Taiwan University. The cells were cultured in a DMEM-HG culture medium with $10 \% \mathrm{FBS}$ and incubated in an incubator at $37{ }^{\circ} \mathrm{C}$ and $5 \%$ $\mathrm{CO}_{2}$. After the cells covered more than $70 \%$, the cells were washed with PBS once. After washing, $1 \mathrm{~mL}$ of trypsin-EDTA was added to detach the cells. The detachment took 4 to $5 \mathrm{~min}$ at $37^{\circ} \mathrm{C}$ and $5 \% \mathrm{CO}_{2}$. 
Then, $9 \mathrm{~mL}$ of culture medium was added to inhibit the activity of trypsin, and the cells were transferred to a $15-\mathrm{mL}$ centrifuge tube for centrifugation for $5 \mathrm{~min}$ at $900 \mathrm{rpm}, 4{ }^{\circ} \mathrm{C}$. The supernatant was removed and an appropriate amount of culture medium was added to resuspend the cells. To estimate the cell concentration, $10 \mu \mathrm{L}$ of the cell suspension was mixed with $10 \mu \mathrm{L}$ of trypan blue. A hemocytometer was then used to determine the concentration of viable cells.

\subsubsection{Cytotoxicity of CuFe NPs}

HeLa cells were seeded into a 96-well plate with $100 \mu \mathrm{L}$ of cell suspension at a concentration of 5000 cells/mL. After $24 \mathrm{~h}$ incubation, the cells were washed by PBS once, and $100 \mu \mathrm{L}$ of culture medium with different metal concentrations of CuFe NPs were added. Then for another $24 \mathrm{~h}$ incubation, the cytotoxicity was determined by MTT assay.

The MTT colorimetric assay is based on the cleavage of MTT by viable cells. The yellow MTT molecule is reduced to purple formazan by mitochondrial enzymes. Since the formation of formazan is directly proportional to the viable cells, MTT assay can determine the relative cell number, indicating the proliferation and cytotoxicity. The relative formazan amount can be determined by reading at the absorbance of $570 \mathrm{~nm}$.

After $24 \mathrm{~h}$ incubation, the culture medium containing NPs was removed, and the cells were washed by PBS once. The MTT working stock was diluted by 10 folds with culture medium as $0.5 \mathrm{mg} / \mathrm{mL} .100 \mu \mathrm{L}$ of culture medium containing MTT was added, and the cells then reacted with MTT for $3.5 \mathrm{~h}$ at $37^{\circ} \mathrm{C}$ and $5 \% \mathrm{CO}_{2}$. Afterward, the medium was removed and $100 \mu \mathrm{L}$ of DMSO was added to dissolve formazan produced by viable cells. After shaking for 30 min avoiding light, the absorbance at $570 \mathrm{~nm}$ was measured by a microplate reader. The blank absorbance was defined as the absorbance of the group with no cells but treated with MTT culture medium for $3.5 \mathrm{~h}$ and then replaced by $100 \mu \mathrm{L}$ DMSO. The activity of cells was defined as the ratio between the NP-treated groups and the non-NP-treated group.

\subsubsection{Temperature Elevation of CuFe NPs}

CuFe NPs were first diluted with DI water to $100 \mathrm{ppm}$ metal. $100 \mu \mathrm{L}$ of $\mathrm{CuFe}$ NPs solution was added into a 96-well plate and then exposed to red laser at the wavelength of $660 \mathrm{~nm}$. The temperature of the solution was detected by a digital thermometer with a thermocouple probe every $30 \mathrm{~s}$ and the temperature elevation was observed.

\subsubsection{Methylene Blue Loading and Purification}

We added $3 \mathrm{mM}$ methylene blue (MB) solution dropwise into $1 \mathrm{~mL}$ CuFe NPs solution and the mixture was rotated avoiding light for $18 \mathrm{~h}$ for $\mathrm{MB}$ absorption. To remove excess $\mathrm{MB}$, the mixture was centrifuged at $11,000 \times g$ for $10 \mathrm{~min}$ and the supernatant was collected for quantification. Using UV-visible spectroscopy (CARY 300nc, Agilent, Santa Clara, CA, USA), the MB calibration curve was first established, and the corresponding amount of $\mathrm{MB}$ absorbed could be estimated. Then, the precipitation was redispersed with $1 \mathrm{~mL}$ of DI water under ultrasonic oscillation. The purification step was repeated three times, and the NP solution was finally redispersed and stored in $1 \mathrm{~mL} \mathrm{DI}$ water for further use.

\subsubsection{Detection of Reactive Oxygen Species from Methylene Blue (MB)-CuFe NPs after Irradiation}

We transferred $1 \mathrm{~mL}$ of the as-synthesized methylene blue-loaded CuFe NPs (abbreviated as MB-CuFe NPs) solution into a $1.5 \mathrm{~mL}$ Eppendorf tube. $2 \mu \mathrm{L}$ of $12.5 \mathrm{mM}$ N,N-dimethyl-4-nitrosoaniline (RNO) and $10 \mu \mathrm{L}$ of $20 \mathrm{mM}$ imidazole were added, and the mixture was vortexed for homogeneous mixing. Then the mixture was irradiated with $660 \mathrm{~nm}$ laser at $75 \mathrm{~mW} / \mathrm{cm}^{2}$ for $10 \mathrm{~min}$, where the distance between the liquid surface and the light source was about $1 \mathrm{~cm}$. Afterward, the Eppendorf tube was covered with aluminum foil to avoid light for further UV-visible examination. 


\subsubsection{Dark Toxicity of the MB-CuFe NPs}

To examine dark toxicity, HeLa cells were seeded into a 96-well plate at a concentration of 5000 cells $/ \mathrm{mL}$. The MB-CuFe NPs solution was first centrifuged to remove DI water and resuspended in culture medium under ultrasonic oscillation. By serial dilution, different concentrations were obtained. After $24 \mathrm{~h}$ incubation, the cells were washed by PBS once, and $100 \mu \mathrm{L}$ of culture medium containing different metal concentrations of CuFe NPs were added. Then, for another $24 \mathrm{~h}$ incubation, the cytotoxicity was determined by MTT assay. The control group was the group that was not co-incubated with nanoparticles.

\subsubsection{Detection of In Vitro Reactive Oxygen Species Generation}

HeLa cells were seeded in a 24-well plate $(12,000$ cells/well) and incubated for $24 \mathrm{~h}$. After removing the medium, the cells were washed with PBS once. $1 \mathrm{~mL}$ of culture medium containing different metal concentrations of MB-CuFe NPs was added and was co-incubated with the cells for $24 \mathrm{~h}$ at $37^{\circ} \mathrm{C}$ and $5 \% \mathrm{CO}_{2}$. After removing the medium, the cells were washed with PBS once. DCFH-DA, a fluorogenic reagent, was used to measure the generation of reactive oxygen species (ROS). The DCFH-DA stock was diluted in culture medium to $20 \mu \mathrm{M}$. Each well was treated with $1 \mathrm{~mL}$ DCFH-DA-containing medium. After incubating for $30 \mathrm{~min}$, the wells were irradiated with a $660 \mathrm{~nm}$ laser at $75 \mathrm{~mW} / \mathrm{cm}^{2}$ for $10 \mathrm{~min}$. Followed by another $60 \mathrm{~min}$ incubation, the reagent was removed and the cells were washed with PBS once. The fluorescence exhibited was observed by fluorescence microscopy, and the fluorescence intensity was quantified by the software Image J (U. S. National Institutes of Health, Bethesda, MD, USA).

\subsubsection{Cell Activity before and after Nanoparticle Treatment under Light Irradiation}

After the synthesis of MB-CuFe NPs, folic acid was conjugated to improve accumulation at the targeted cells. $4 \mathrm{mg}$ EDC and $4 \mathrm{mg}$ NHS were separately dissolved in $400 \mu \mathrm{L}$ of DI water and then mixed. $200 \mu \mathrm{L}$ of this EDC/NHS solution was afterward mixed with $600 \mu \mathrm{L}$ of DI water and $50 \mu \mathrm{L}$ of $0.05 \mathrm{M}$ folic acid, followed by sonication for 5 min avoiding light. Then, $200 \mu \mathrm{L}$ of the NP sample solution was added to the previously prepared mixture. It was sonicated for $60 \mathrm{~min}$ under an ice bath, centrifuged for $10 \mathrm{~min}$ to remove supernatant, and resuspended with culture medium for use. Different metal concentrations were prepared by serial dilution. HeLa cells, which had been seeded and incubated for $24 \mathrm{~h}$ at the density of 12,000 cells/well in a 24-well plate, were treated with the medium of different metal concentrations for $4 \mathrm{~h}$. After $4 \mathrm{~h}$, the medium was removed, and the cells were rinsed with PBS once and refreshed with non-NP-containing medium. Then, each well was irradiated with $660 \mathrm{~nm}$ laser at $75 \mathrm{~mW} / \mathrm{cm}^{2}$ for $10 \mathrm{~min}$. After irradiation, the cells were incubated for another $24 \mathrm{~h}$. Lastly, the cell activity was determined by MTT assay to compare between the results before and after light treatment.

\subsubsection{Statistical Analysis}

All data were expressed as means \pm standard deviation. A comparison of different groups was determined using one-way analysis of variance (ANOVA) and a significant difference was assumed at $p$ value $\leq 0.05$.

\section{Results}

\subsection{Research Outcomes}

\subsubsection{Characterization of CuFe NPs}

Figure 1a shows the UV-visible absorption spectrum of CuFe NPs with different $\mathrm{Fe} / \mathrm{Cu}$ ratios. For groups with lower Fe/Cu ratios (namely, 0-4), absorption peaks at the wavelength between $580 \mathrm{~nm}$ and $600 \mathrm{~nm}$ were obtained, meaning the LSPR behavior of nano-sized copper appeared [56-58]. 
As the Fe/Cu ratio went higher than 5, these peaks were no longer observable in groups. An absorbance peak with an $\mathrm{Fe} / \mathrm{Cu}$ ratio equal to 2 slightly shifted to $660 \mathrm{~nm}$, while the $\mathrm{Fe} / \mathrm{Cu}=0$ group had an absorbance peak at $580 \mathrm{~nm}$. The redshift wavelength is close to the NIR-I wavelength window. Although the Fe/Cu of CuFe NPs at 2 provided significant benefit for NIR light absorption, the extinction at 580-600 nm remarkably decreased. Thus, the subsequent PDT treatment with the lower power threshold did not show a photothermal injury without side effects by heat during a long PDT reaction period.
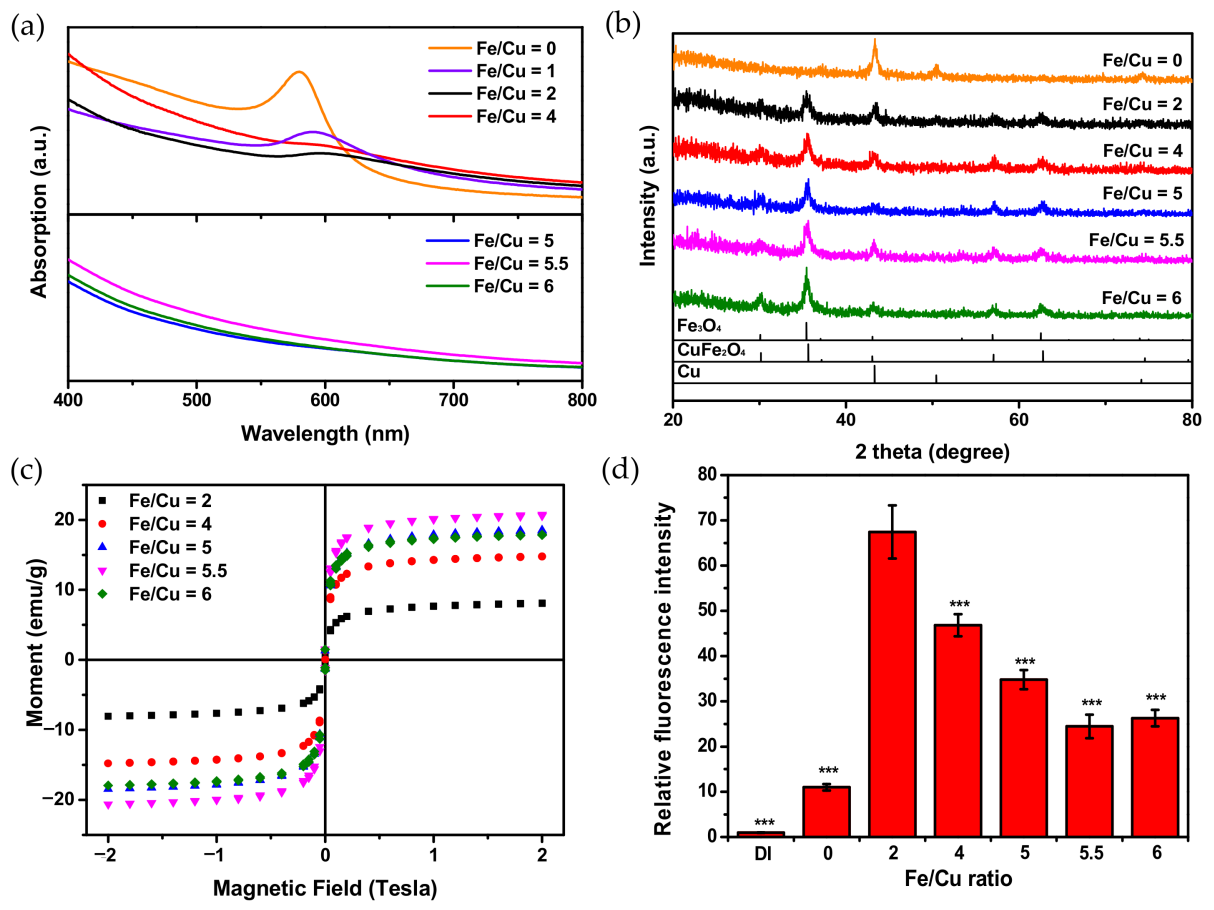

Figure 1. (a) UV-visible spectrum and (b) X-ray diffraction (XRD) pattern of CuFe nanoparticles (NPs). (c) Hysteresis loops of CuFe NPs with different Fe/Cu ratios. (d) Quantification of $\mathrm{H}_{2} \mathrm{O}_{2}$ catalytic ability by $2^{\prime}, 7^{\prime}$-dichlorofluorescein diacetate (DCFH-DA, $n=4$. ${ }^{* * *} p<0.001$, compared to Fe/Cu ratio of 2 ).

The composition of metallic $\mathrm{Cu}$ and ferrite structure in the $\mathrm{CuFe}$ NPs was determined by taking XRD measurements (Figure $\mathrm{lb}$ ). In the $\mathrm{Cu}$ only group (Fe/Cu ratio of 0 ), the pure $\mathrm{Cu}$ nanoparticle was produced without the ferrite impurity's reflection peaks. When including $6.21 \mathrm{mM} \mathrm{Fe} \mathrm{(Fe/Cu} \mathrm{ratio}$ of 2), the XRD spectrum revealed the new reflection pattern related to the cubic spinel structures of $\mathrm{Fe}_{3} \mathrm{O}_{4}$ and/or $\mathrm{CuFe}_{2} \mathrm{O}_{4}[59,60]$. Note that the reflection peak intensity of $2 \theta$ at $50.43^{\circ}$ decreased with the increased iron reagent concentration from $\mathrm{Fe} / \mathrm{Cu}$ at 0 to $\mathrm{Fe} / \mathrm{Cu}$ at 4 . Therefore, the absorbance decline at 580-660 $\mathrm{nm}$ was attributed to the decreased $\mathrm{Cu}$ population in CuFe NPs.

After the synthesis and purification processes were complete, the CuFe NPs were well dispersed in DI water. The copper and iron concentrations of each group were quantified by atomic absorption. As shown in Figure S1a, the Fe concentration of NPs increased as the Fe/Cu ratio of the reactant increased. In the groups with a higher Fe/Cu reactant ratio, the product's Fe concentration slightly decreased. In contrast, the copper concentration declined as the $\mathrm{Fe} / \mathrm{Cu}$ ratio in the reactant increased (Figure S1b). Since Fe's initial concentration manipulated the $\mathrm{Fe} / \mathrm{Cu}$ ratio of nanoproducts, the decreased $\mathrm{Cu}$ concentration could be attributed to the increase in Fe ions competing for reduction. Figure S1c shows the Fe/Cu molar ratio. Although the Fe concentration of the nanoproducts decreased when the reactant ratio was over 5, the Fe/Cu molar ratio still increased. The decrease of the metallic $\mathrm{Cu}$ crystal in the XRD measurement (Figure 1b) appeared to be due to the dissolution and release in the solution, which could allow the $\mathrm{Cu}$ ion source into the copper ferrite lattice. However, we observed that the decrease in $\mathrm{Cu}$ concentration in the product resulted in inconsistent $\mathrm{Fe} / \mathrm{Cu}$ ratios in the batch-prepared products. 
In addition, TEM images were used to analyze these CuFe NPs, as shown in Figure S2, where it can be seen that a dark contrast appeared in the center, showing the inorganic composites embedded in the light-contrasting PSMA polymer. Such a composition was similar to the previous core-shell structure. As the amount of $\mathrm{FeCl}_{2}$ added increased in the same reaction, the single inorganic core in the particles was converted into a multi-core nanostructure with a spindle-like shape. Moreover, the polymer encapsulating inorganic nanocores had a higher yield with the increment of the loading iron concentration. These CuFe NPs were oval, as shown in the TEM images. However, the shape of the CuFe NPs became irregular and turned to aggregates when the Fe/Cu ratio increased to 6. According to the statistics, the average diameter was $66.04 \pm 9.65,70.99 \pm 11.75,115.89 \pm 34.37$, $97.87 \pm 30.67,118.37 \pm 34.90$, and $90.57 \pm 27.04 \mathrm{~nm}$ for $\mathrm{Fe} / \mathrm{Cu}$ ratios of $0,2,4,5,5.5$, and 6 respectively (Figure S3). Moreover, the average core diameter was $21.33 \pm 9.24 \mathrm{~nm}$ for the single-core structure, indicating the average thickness of the PSMA shell was $22.35 \pm 13.36 \mathrm{~nm}$.

To characterize the colloidal dispersivity of CuFe NPs in aqueous phase, DLS was applied to determine the hydrodynamic diameter and zeta potential (Table S2). The polydispersity index (PdI) of each group was lower than 0.3 , representing the uniformity of the CuFe NPs. The zeta potential determined the negatively charged surface property of the CuFe NPs to be around $-30 \mathrm{mV}$, indicating the exposure of carboxylate groups at PSMA polymer in the inorganic core-polymer shell structure. A considerable charge value could provide enough electrostatic repulsion to aid the colloid dispersion in the aqueous solution.

\subsubsection{Magnetic Attraction}

To examine whether CuFe NPs are able to respond to a magnetic field, a cylinder-shaped neodymium magnet was used to attract the as-prepared CuFe NPs (Figure 2). For the groups with Fe, $\mathrm{CuFe}$ NPs gathered at the magnet within $15 \mathrm{~min}$. The aggregation could also be resuspended in DI water by 3-s vortexing. The group with an $\mathrm{Fe} / \mathrm{Cu}$ ratio of 0 showed no response to the magnetic field because there was weak magnetization of $\mathrm{Cu}$ in the crystal. However, the appearances of different groups showed no clear difference. Further magnetic properties were characterized by a B-H Curvehysteresis loop. The hysteresis loops of $\mathrm{CuFe}$ NPs with different Fe/Cu ratios were measured by a superconducting interference magnetometer (Figure 1c). The saturation magnetization value increased with the $\mathrm{Fe} / \mathrm{Cu}$ ratio, which was consistent with the high magnetization of Fe combined in the ferrite crystals. The saturation magnetization values of groups of the $\mathrm{Fe} / \mathrm{Cu}$ ratio were $8.14 \mathrm{emu} / \mathrm{g}$ at 2, $14.77 \mathrm{emu} / \mathrm{g}$ at $4,18.53 \mathrm{emu} / \mathrm{g}$ at $5,20.75 \mathrm{emu} / \mathrm{g}$ at 5.5 , and $17.88 \mathrm{emu} / \mathrm{g}$ at 6 . Note that the decreased magnetization occurred at an $\mathrm{Fe} / \mathrm{Cu}$ ratio equal to 6 because of the possible increase in the antiferromagnetic property in the ferrite crystal host. In addition, the magnetic loops lacked remanent magnetization for all the CuFe NP samples. The intersection of the x-axis, representing the coercivity, was also smaller than $10 \mathrm{Oe}$, exhibiting a typical superparamagnetic behavior. It has been reported that superparamagnetic nanomaterials can align the magnetic moment from the dispersion phase to the targeted direction in the lesion area when the magnetic field-guiled operation is performed. Furthermore, the feasibility of superparamagnetic nanoparticles with strong magnetization serving as an MRI agent was already proven in several studies in vitro or in vivo $[37,61,62]$.

\subsubsection{Enhanced Conversion of $\mathrm{H}_{2} \mathrm{O}_{2}$ to ROS with CuFe NPs}

$\mathrm{H}_{2} \mathrm{O}_{2}$ is an indispensable intermediate in cell death, generating reactive oxygen species (ROS) to induce the apoptosis process. The DCFH-DA molecule was utilized to quantify the conversion of $\mathrm{H}_{2} \mathrm{O}_{2}$ to generate ROS with $\mathrm{CuFe}$ NPs. CuFe NPs, acted as catalyst, could perform a Fenton-like catalysis reaction. Figure $1 \mathrm{~d}$ shows the relative intensity of the DCF fluorescence. As the Fe/Cu ratio decreased from 6 to 2, increasing $\mathrm{Cu}$ concentration, the fluorescence intensity increased. However, the group with $\mathrm{Fe} / \mathrm{Cu}$ ratio of 0 , consisting of the only $\mathrm{Cu}$, produced weak fluorescence, indicating low conversion efficiency from $\mathrm{H}_{2} \mathrm{O}_{2}$ to ROS. The result indicated that the combination of $\mathrm{Fe}$ with $\mathrm{Cu}$ in 
the oxide form could enhance the catalytic ability to generate ROS [63-65]. The optimal Fe/Cu ratio of 2 was shown to have reached the highest conversion rate.

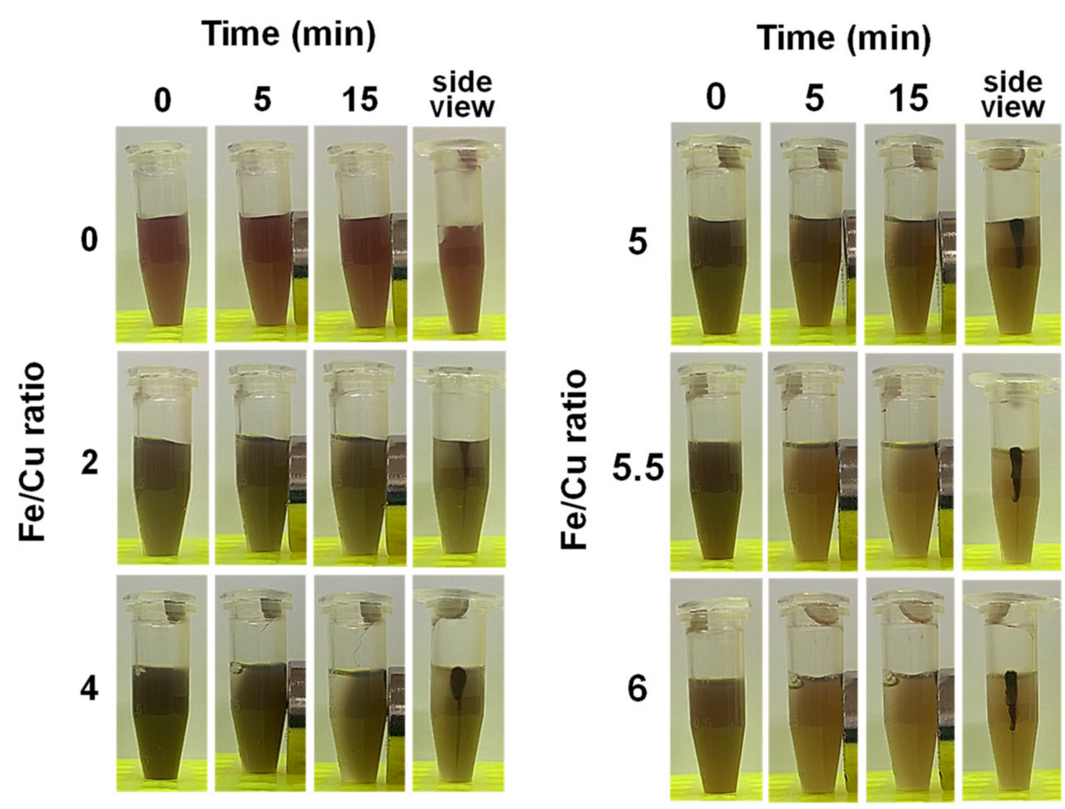

Figure 2. Photos of CuFe NPs under magnetic field after 0, 5, 15 min and the side view of CuFe NPs under magnetic field after $15 \mathrm{~min}$.

\subsubsection{Degradability Test}

To quantify the degradability of $\mathrm{CuFe} N \mathrm{NPs}$, the nanoparticles were dispersed in five different kinds of solvent, including PBS ( $\mathrm{pH}=7.4$ ), acidic PBS ( $\mathrm{pH}=4.5)$, DI water, culture medium, and $0.5 \%$ $\mathrm{H}_{2} \mathrm{O}_{2}$. The nano-precipitates were centrifuged and collected at different time intervals, and the metal concentrations from the separated supernatant were quantified. As shown in Figure S4, it was found that the Fe ions of the samples did not degrade in any solvent, where the remaining Fe concentration was around $100 \%$. The dissolution of $\mathrm{Cu}$ ions from the CuFe NPs was not determined in DI water and neutral PBS. However, we found that the $\mathrm{Cu}$ ions were dissolved in acidic PBS within $8 \mathrm{~h}$ (Figure S5). It was proposed that the nano-sized $\mathrm{Cu}$ species could react with $\mathrm{H}+$. The dissolution proportion varied with the $\mathrm{Fe} / \mathrm{Cu}$ ratio; it was $23.29 \%$ at $0,46.34 \%$ at $2,64.52 \%$ at $4,85.00 \%$ at $5,87.50 \%$ at 5.5 , and $86.67 \%$ at 6 . In addition, most groups reach the maximum amount of dissolution within $8 \mathrm{~h}$, whereas the group with an $\mathrm{Fe} / \mathrm{Cu}$ ratio of 4 displayed slightly different behavior, where the remaining copper percentage continued to drop after $8 \mathrm{~h}$ and the dissolution proportion reached $77.42 \%$ after $16 \mathrm{~h}$. Similarly, Cu was dissolved in the culture medium. This result could be attributed to the salt, proteins, antibiotics, and other substances in the culture medium, which might react with $\mathrm{Cu}$ and lead to ionization.

\subsubsection{Cytotoxicity}

The cytotoxicity of CuFe NPs was quantified by MTT assay after $24 \mathrm{~h}$ co-incubation with HeLa cells (Figure S6). Compared to the group with a Fe/Cu ratio of 0 , all the other groups exhibited significantly lower cytotoxicity from $2 \mathrm{ppm}$ to $100 \mathrm{ppm}$ (all $p$-values $<0.001$ ). The cell viability rose as the $\mathrm{Fe} / \mathrm{Cu}$ ratio increased, corresponding to a decreased $\mathrm{Cu}$ proportion in $\mathrm{CuFe}$ NPs. For $\mathrm{CuFe}$ NPs containing Fe, the HeLa cells' cell viability was not influenced when the metal concentration was under $5 \mathrm{ppm}$. The cell activity of all groups with Fe was over $60 \%$ at a concentration of $50 \mathrm{ppm}$.

Although the group with an $\mathrm{Fe} / \mathrm{Cu}$ ratio of 2 had the most significant $\mathrm{H}_{2} \mathrm{O}_{2}$ catalytic ability (Figure 1d), the CuFe NPs showed much-improved cell viability when compared with the group with an $\mathrm{Fe} / \mathrm{Cu}$ ratio of 0 (Figure $\mathrm{S6}$ ). When the concentration exceeded $5 \mathrm{ppm}$, toxicity was observed and increased with concentration. The cell activity of all groups with Fe was over $75 \%$ at a concentration 
of 0-25 ppm. Based on the dose-dependent results, the low dose of this CuFe NP was selected for further experiments.

\subsubsection{Temperature Elevation}

Photothermal therapy is based on the characteristic that cells undergo irreversible death processes when the temperature exceeds $48 \mathrm{~h}$. The temperature elevation of groups with $\mathrm{Fe} / \mathrm{Cu}$ ratios at 0 and 2, at a metal concentration of 100 ppm, were measured and are shown in Figure 3a,b. Both groups in DI water elevated the temperature by at least $10{ }^{\circ} \mathrm{C}$ higher than DI water only, and the group with an $\mathrm{Fe} / \mathrm{Cu}$ ratio of 2 showed higher temperature elevation efficiency. The result that the group with an $\mathrm{Fe} / \mathrm{Cu}$ ratio of 2 could contribute to a larger temperature difference than that at 0 is worth noting. The measurement of temperature elevation was based on the same metal concentration, meaning the $\mathrm{Cu}$ concentration of the group with an $\mathrm{Fe} / \mathrm{Cu}$ ratio of 2 was only $20 \%$ of that of the group with $\mathrm{Cu}$ only. Since the extinction coefficient of $\mathrm{Cu}$ is greater than that of $\mathrm{Fe}$, the temperature elevation of the group with $\mathrm{Cu}$ only was expected to be higher $[15,29,66]$. However, the result was the opposite, meaning that $\mathrm{Fe}$ could assist with $\mathrm{Cu}$ 's temperature elevation. The temperature elevation in the culture medium was also measured. The behaviors of the three tested groups were similar but showed slightly lower temperature differences than those in DI water because the substances in the culture medium might absorb light and poorly transfer the energy into heat. The temperature elevation of the culture medium only being higher than that of DI water also confirmed the assumption.

(a)

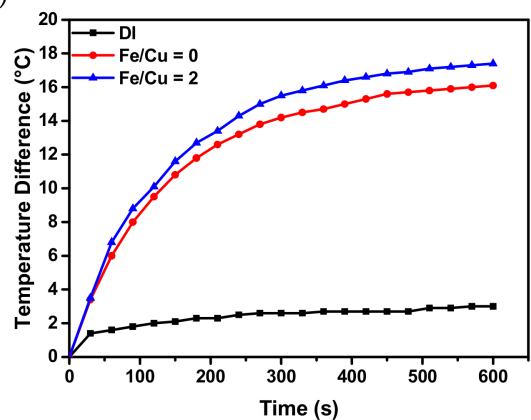

(c)

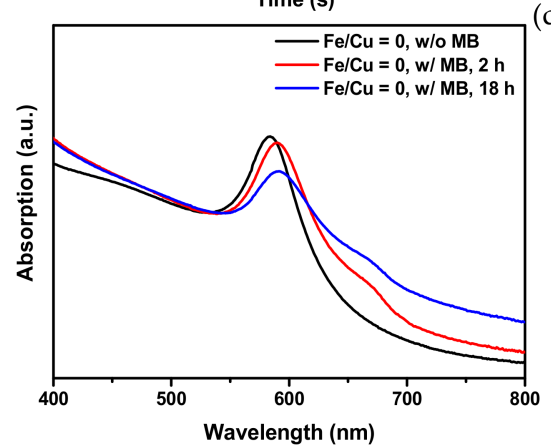

(b)

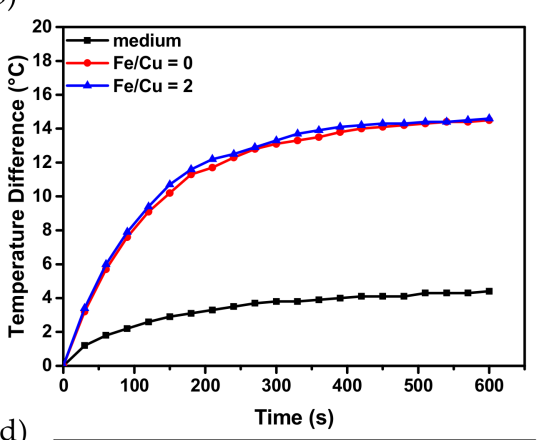

(d)

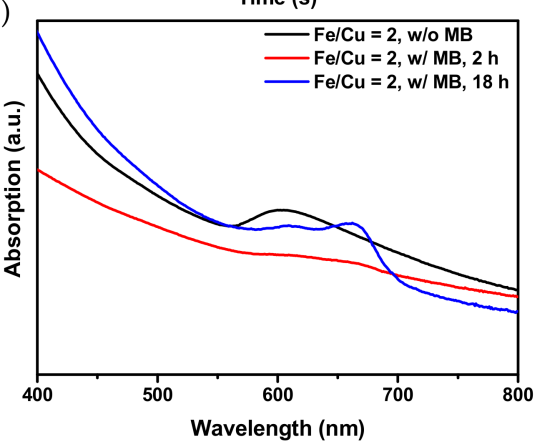

Figure 3. (a) The photothermal effect of CuFe NPs at $100 \mathrm{ppm}$ metal with $\mathrm{Fe} / \mathrm{Cu}$ ratio of 0 and 2 in DI water or in (b) culture medium. (c) The UV-visible spectrum of methylene blue (MB)-CuFe NPs of $\mathrm{Fe} / \mathrm{Cu}$ ratio of 0 and (d) 2 at different reaction times. Note that $\mathrm{MB}$ has an absorbance peak at a wavelength of $660 \mathrm{~nm}$.

\subsubsection{Structures and Optical Properties of MB-Immobilized CuFe NPs}

According to previous examinations, an $\mathrm{Fe} / \mathrm{Cu}$ ratio of 2 was chosen as the experimental group on $\mathrm{MB}$ immobilization and its extended properties, whereas $\mathrm{Fe} / \mathrm{Cu}$ ratio of 0 was taken as the control group. After immobilizing methylene blue (MB), the TEM images showed no obvious change in morphology compared to the CuFe NPs (Figure 4). This result provided direct evidence that MB immobilization 
did not destroy the NP structure, as demonstrated by the lack of destruction at the surface and the core area of CuFe NPs.
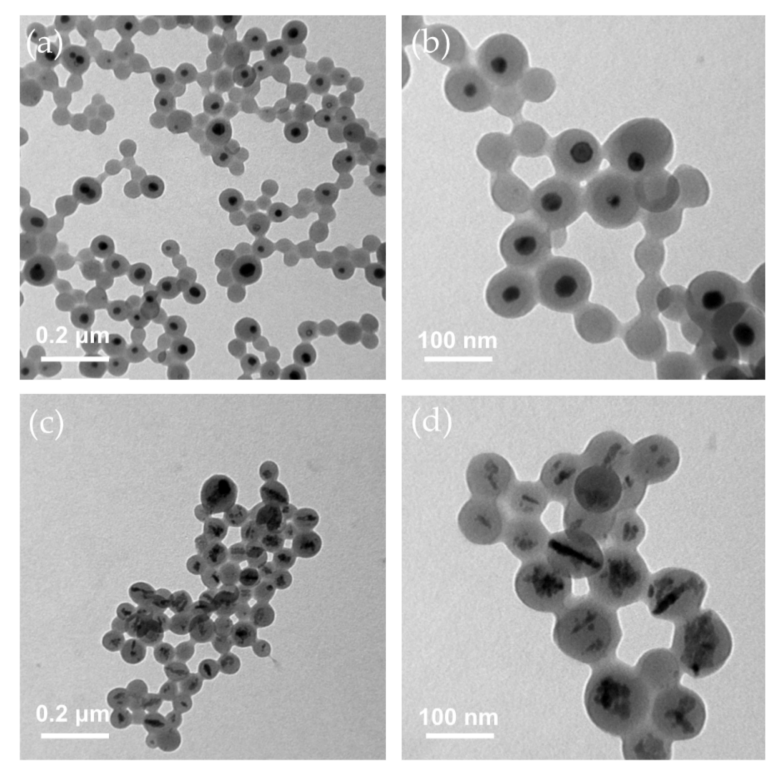

Figure 4. Transmission electron microscopy (TEM) images of CuFe NPs. (a,b) Fe/Cu ratio of 0 shows a single-core structure. (c,d) $\mathrm{Fe} / \mathrm{Cu}$ ratio of 2 shows a multi-core structure.

As shown in Figure 3c,d, the UV-visible spectrum of the MB-immobilized CuFe NPs exhibited an obvious peak at $660 \mathrm{~nm}$, while CuFe NPs did not possess specific peaks. MB has the strongest characteristic absorption peak at $660 \mathrm{~nm}$. Both results demonstrated the successful immobilization of $\mathrm{MB}$ onto the surface of CuFe NPs. Moreover, our tests showed that MB loading efficacy was higher after an 18-h incubation time than that under the same reaction with a 2-h incubation.

\subsubsection{Size Distribution, Zeta Potential, and Drug Loading Content of MB-Immobilized CuFe NPs}

Following MB conjugation, the average hydrodynamic diameter slightly increased in both groups, suggesting MB's existence on the surface of the NPs (Figure 5a). To further examine this assumption, the zeta potential was measured. After the reaction, the zeta potential for the groups with $\mathrm{Fe} / \mathrm{Cu}$ ratios of 0 and 2 increased from -30.27 and $-33.13 \mathrm{mV}$ to -21.73 and $-16.40 \mathrm{mV}$, respectively (Figure $5 \mathrm{~b}$ ). Since MB is positively charged, the results confirmed the successful conjugation of MB. As for the drug loading content, the amount of MB loaded was also assessed. The MB concentration in the final product was calculated to be $30-50 \mu \mathrm{M}$ at a metal concentration of $25 \mathrm{ppm}$, which was high enough for photodynamic therapy.

\subsubsection{Detection of Reactive Oxygen Species after Irradiation}

RNO shows a pronounced absorption peak at $440 \mathrm{~nm}$, but the peak declines if reactive oxygen species are generated $[53,67]$. Figure $5 c$ clearly showed a significant decrease in absorbance at $440 \mathrm{~nm}$ as a function of irradiation time after $660 \mathrm{~nm}$ laser irradiation. This result suggests that MB-CuFe NPs could induce ROS generation, thereby being a potential photodynamic therapy agent. 
(a)

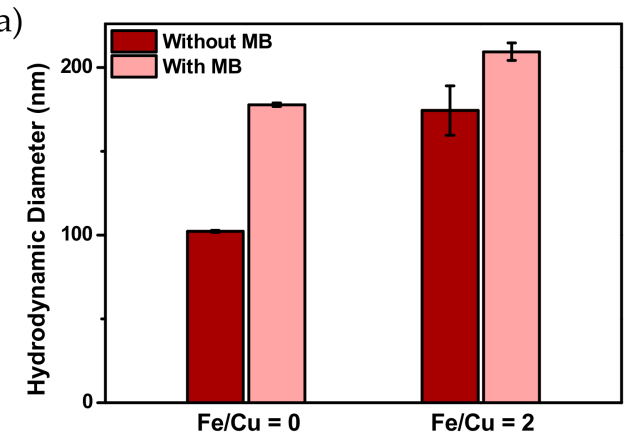

(c)

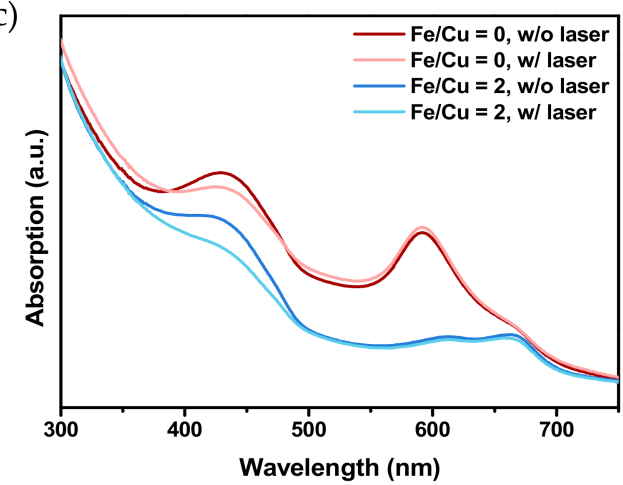

(b)

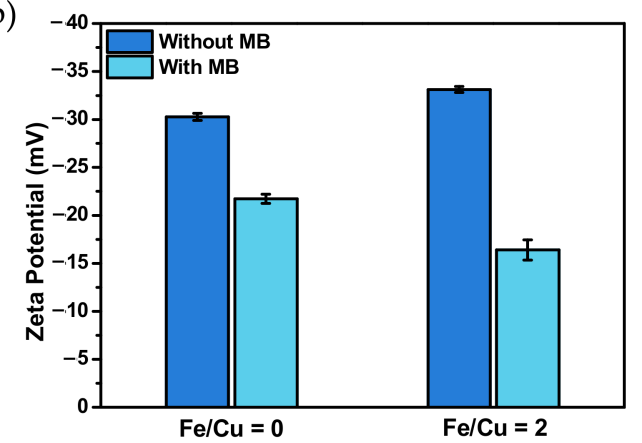

(d)

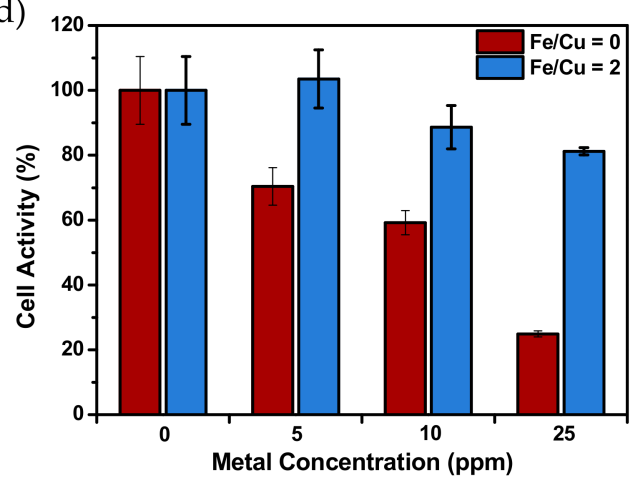

Figure 5. (a) Hydrodynamic diameter and (b) zeta potential of MB-CuFe NPs before and after MB conjugation. (c) The UV-visible spectrum of the N,N-dimethyl-4-nitrosoaniline (RNO)/imidazoletreated MB-CuFe NPs solution before and after laser irradiation for $10 \mathrm{~min}$. The peak at $440 \mathrm{~nm}$ indicates the existence of RNO reagent, which can be degraded by reactive oxygen species (ROS). (d) Cell activity of cervical cancer HeLa cells after $24 \mathrm{~h}$ co-incubation with MB-CuFe NPs. Over $80 \%$ of the cells are viable at a metal concentration of $25 \mathrm{ppm}$ in the group with an $\mathrm{Fe} / \mathrm{Cu}$ ratio of 2.

\subsubsection{Dark Toxicity of CuFe NPs}

The MTT assay was applied to evaluate the cell activity of HeLa cells after being co-incubated with MB-CuFe NPs for $24 \mathrm{~h}$ (Figure 5d). Compared to the group with an Fe/Cu ratio of 0, the group with an $\mathrm{Fe} / \mathrm{Cu}$ ratio of 2 showed a much higher metabolic activity, and the cell activity remained above $80 \%$ at a metal concentration of $25 \mathrm{ppm}$. Since $\mathrm{Cu}$ is less biocompatible, under the same metal concentration, the group with an $\mathrm{Fe} / \mathrm{Cu}$ ratio of 0 had a higher proportion of $\mathrm{Cu}$ and would induce higher toxicity.

\subsubsection{In Vitro Reactive Oxygen Species Generation}

Different metal concentrations under $25 \mathrm{ppm}$ in both groups were applied in the in vitro experiments. HeLa cells were first co-incubated with the MB-immobilized CuFe NPs for $24 \mathrm{~h}$, washed with PBS, and then refreshed with DCFH-DA-containing medium for another 30 min. Afterward, the cells were irradiated with laser for $10 \mathrm{~min}$, further incubated for $60 \mathrm{~min}$, and then observed with fluorescence microscopy to determine the ROS generated in cells. Figure 6 shows that the fluorescence was barely detected in the group with an $\mathrm{Fe} / \mathrm{Cu}$ ratio of 0 . In contrast, the fluorescence signal was more significant in the group with an $\mathrm{Fe} / \mathrm{Cu}$ ratio of 2, even at a low metal concentration of $5 \mathrm{ppm}$. As the metal concentration increased, the DCF performance also improved. This may be attributed to the higher MB concentration, which would induce more ROS generation after irradiation. Furthermore, the MTT results showed significant differences before and after laser irradiation (Figure 7). Since the cells were co-incubated with the nanoparticles for $4 \mathrm{~h}$ only and showed lower activity after irradiation, it was inferred that the cells might take in the nanoparticles through endocytosis. With the help of laser irradiation, the endocytosed nanoparticles could spark the generation of more ROS within the cells, therefore accelerating the progress of reaching the apoptosis phase and finally leading to cell death. 

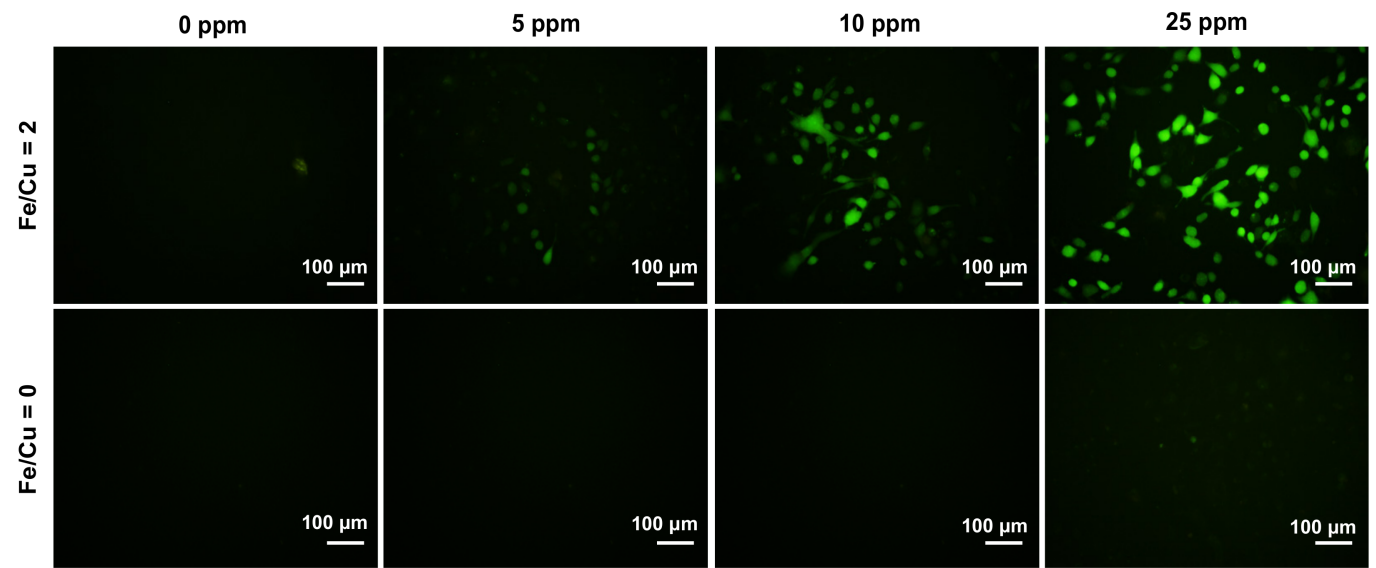

Figure 6. DCFH-DA fluorescence performance at different metal ratios and different metal concentrations. The stronger fluorescence signal indicates more ROS are generated. (Scale bar: $100 \mu \mathrm{m}$ ).

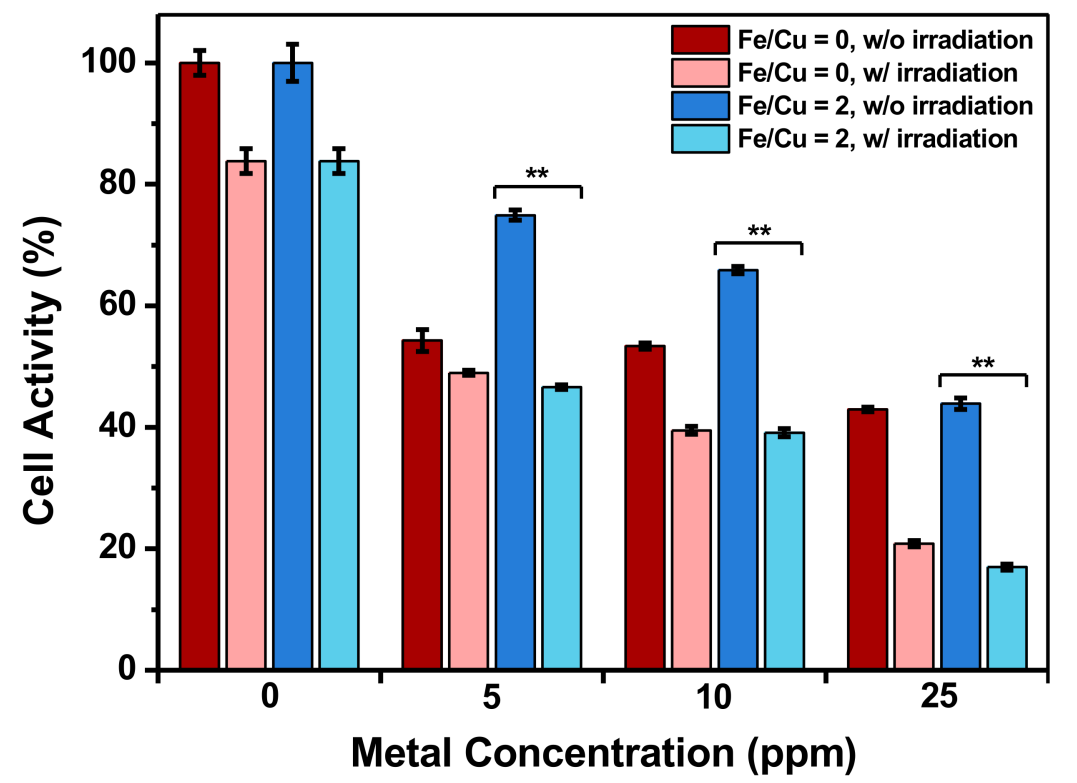

Figure 7. Cell activity of HeLa cells with and without laser irradiation. (** $p<0.01$; MB-CuFe NPs co-incubation time: $4 \mathrm{~h}$ ).

\section{Discussion}

Dual-metal nanoparticles encapsulated into PSMA polymer layer was developed to perform a combined optical and magnetic function in this work. The hydrothermal reaction of $\mathrm{FeCl}_{2}$, $\mathrm{N}_{2} \mathrm{H}_{4}$, and PSMA has been demonstrated to fabricate $\mathrm{Fe}_{3} \mathrm{O}_{4} @ P S M A$ nanoparticles by Huang and co-workers [13]. Because of the similar lattice constant between $\mathrm{Fe}_{3} \mathrm{O}_{4}$ and $\mathrm{CuFe}_{2} \mathrm{O}_{4}$ crystal [58,59], the incorporation of $\mathrm{Cu}$ ions into the spinel structure was allowed to generate high crystalline nanoparticles. The formation of the anisotropic nanostructure of CuFe NPs can be attributed to the kinetic control crystallization process [68] relying on the mixture of $\mathrm{Cu}$ ions into the iron oxide crystal by dissolution of $\mathrm{Cu}$ NPs (Figure $4 \mathrm{a}, \mathrm{b}$ ) rather than direct co-precipitation reaction upon the simple mixture of $\mathrm{Fe}$ and $\mathrm{Cu}$ ions in a base condition $[43,69]$.

Although the group with an $\mathrm{Fe} / \mathrm{Cu}$ ratio of 2 had the most significant $\mathrm{H}_{2} \mathrm{O}_{2}$ catalytic ability (Figure 1d), the CuFe NPs showed much-improved cell viability when compared with the group with an $\mathrm{Fe} / \mathrm{Cu}$ ratio of 0 (Figure S6). When the concentration exceeded $5 \mathrm{ppm}$, toxicity was observed and increased with concentration. The cell activity of all groups with Fe was over $75 \%$ at a concentration of 0-25 ppm. Based on the dose-dependent results, the low dose of this CuFe NP was selected for further experiments. 
It has been reported that hydrogen peroxide plays an important role in cancer development, where $\mathrm{H}_{2} \mathrm{O}_{2}$ was found to be highly produced by cancer cells [40]. Several reports presented ROS-induced chemodynamic therapy as being strongly evolved from the cancer cells in the presence of the iron-based nanoparticles [43,70-72]. The chemodynamic effect is commonly inferior to normal cells because the malignant cells possessed high intracellular $\mathrm{H}_{2} \mathrm{O}_{2}$ levels compared with normal cells. As a proof-of-concept, in our work, the DCF was utilized to evaluate the potential application of the Fenton-like catalysis reaction with CuFe NP catalyst to generate toxic ROS by converting the intracellular $\mathrm{H}_{2} \mathrm{O}_{2}$ (Figures $1 \mathrm{~d}$ and 6). Following optimization of the Fe/Cu ratio, an FDA-approved photosensitizer, methylene blue (MB), was conjugated with CuFe NPs to improve PDT efficacy. The surface charge discrepancy confirms the adsorption of MB onto the surface of CuFe NPs (Figure 5b). Compared to previous reports, the optimal $\mathrm{MB}$ concentration in our work is considered high enough to improve PDT efficacy [73,74]. After $10 \mathrm{~min}$ of $660 \mathrm{~nm}$ irradiation, the in vitro results showed that the efficient PDT killed over $40 \%$ more HeLa cells at the sample dose of 5 ppm, compared to the non-irradiated group (Figures 6 and 7). Although several works have focused on the iron-copper composite Fenton catalysts [75,76], the use of highly dispersed anisotropic CuFe NPs for enhancing the conversion of $\mathrm{H}_{2} \mathrm{O}_{2}$ to bio-stimulate cancer cells and combined with PDT has not been reported.

Noble metal nanocomposites, such as Ag/Au nanocage, spiky star-shaped Au/Ag NPs and $\mathrm{Ag} / \mathrm{Nd}$ NPs, were proposed as potential materials for photothermal therapy [77-79]. However, the Au alone and Ag-based NPs lacked the magnetic property for an imaging application of MRI [80] and could not efficiently generate ROS via the conversion of $\mathrm{H}_{2} \mathrm{O}_{2}$ molecules. Because the photothermal effect may contribute an additional heat transport process to harm the cells and induce endogenous $\mathrm{H}_{2} \mathrm{O}_{2}, \mathrm{CuFe} \mathrm{NP}$ was promising in further PTT/PDT therapeutic strategies. It is noteworthy that the anisotropic CuFe NPs increased their particle size in length (Figure 4c,d and Figure S2) and thus were suitable and conducive to the enhanced permeability and resonance (EPR) effect by passively targeting solid tumor tissues [81-84]. In addition, the $\mathrm{Cu} / \mathrm{Fe}$ composite in the CuFe NPs was degradable (Figure S5) to possibly prevent long-term retention and improve the biocompatibility for the potential photomedicine development.

\section{Conclusions}

In summary, we devised copper-iron bimetallic nanoparticles loaded with methylene blue (MB-CuFe NPs) for photodynamic/photothermal combined therapy. Through the one-step hydrothermal reaction, the facile synthesis process allows the mass production of the CuFe NPs. The incorporation of Fe not only causes a redshift in the UV-visible spectrum but also renders the nanoparticle superparamagnetic. Besides, the outstanding $\mathrm{H}_{2} \mathrm{O}_{2}$ catalytic ability further improves ROS generation. Therefore, CuFe NPs serve not only as a photocatalyst but also as a possibly effective photothermal agent and even a potential bioimaging resource, while MB enhances ROS generation and facilitates in vitro PDT therapeutic effects. To our knowledge, this study on CuFe NPs hybridized with MB could be a further development of MRI-guided combined phototherapy, which may shed light on a new concept of cancer treatment.

Supplementary Materials: The following are available online at http://www.mdpi.com/2079-4991/10/12/2429/s1, Figure S1: Metal ratio and UV-Vis spectrum of CuFe NPs, Figure S2: TEM images of CuFe NPs with different metal ratios, Figure S3: Statistics of the average diameter of CuFe NPs with different metal ratios, Figure S4: Relative remaining Fe of $\mathrm{CuFe}$ NPs after $16 \mathrm{~h}$ dispersion in different solvents at $25^{\circ} \mathrm{C}$, Figure S5: Relative remaining $\mathrm{Cu}$ of CuFe NPs after $16 \mathrm{~h}$ dispersion in different solvents at $25^{\circ} \mathrm{C}$, Figure S6: Cell activity of HeLa cells after $24 \mathrm{~h}$ co-incubation with CuFe NPs, Table S1: Formula of synthesis of CuFe NPs, Table S2: Hydrodynamic diameter and zeta potential of CuFe NPs.

Author Contributions: Conceptualization, M.-Y.L.; methodology, M.-Y.L.; software, S.-H.K. and P.-T.W.; validation, S.-H.K. and J.-Y.H.; formal analysis, P.-T.W. and C.-P.C.; data curation, M.-Y.L.; writing-original draft preparation, S.-H.K. and M.-Y.L.; writing—review and editing, M.-Y.L.; supervision, J.Y. and M.-Y.L.; project administration, J.Y. and M.-Y.L. All authors have read and agreed to the published version of the manuscript.

Funding: This work was supported in part by grants from the National Science Council, Taiwan (MOST 1092113-M-153-001-, MOST 108-2113-M-153-001- and MOST 109-2221-E-002-101-). 
Conflicts of Interest: The authors declare no conflict of interest.

\section{References}

1. Wang, Y.; De, S.; Yan, N. Rational control of nano-scale metal-catalysts for biomass conversion. Chem. Commun. 2016, 52, 6210-6224. [CrossRef] [PubMed]

2. Tran, S.; DeGiovanni, P.-J.; Piel, B.; Rai, P. Cancer nanomedicine: A review of recent success in drug delivery. Clin. Transl. Med. 2017, 6, 44. [CrossRef]

3. Liu, T.-M.; Conde, J.; Lipiński, T.; Bednarkiewicz, A.; Huang, C.-C. Revisiting the classification of NIR-absorbing/emitting nanomaterials for in vivo bioapplications. NPG Asia Mater. 2016, 8, e295. [CrossRef]

4. Kim, D.; Lee, N.; Park, Y.I.; Hyeon, T. Recent advances in inorganic nanoparticle-based NIR luminescence imaging: Semiconductor nanoparticles and lanthanide nanoparticles. Bioconjug. Chem. 2017, 28, 115-123. [CrossRef] [PubMed]

5. Ahmadivand, A.; Gerislioglu, B.; Ahuja, R.; Mishra, Y.K. Terahertz plasmonics: The rise of toroidal metadevices towards immunobiosensings. Mater. Today 2020, 32, 108-130. [CrossRef]

6. Ahmadivand, A.; Gerislioglu, B.; Ramezani, Z.; Ghoreishi, S.A. Attomolar detection of low-molecular weight antibiotics using midinfrared-resonant toroidal plasmonic metachip technology. Phys. Rev. Appl. 2019, 12, 034018. [CrossRef]

7. Ahmadivand, A.; Gerislioglu, B.; Tomitaka, A.; Manickam, P.; Kaushik, A.; Bhansali, S.; Nair, M.; Pala, N. Extreme sensitive metasensor for targeted biomarkers identification using colloidal nanoparticles-integrated plasmonic unit cells. Biomed. Opt. Express 2018, 9, 373-386. [CrossRef]

8. Albanese, A.; Tang, P.S.; Chan, W.C. The effect of nanoparticle size, shape, and surface chemistry on biological systems. Annu. Rev. Biomed. Eng. 2012, 14, 1-16. [CrossRef] [PubMed]

9. Craciun, A.M.; Focsan, M.; Magyari, K.; Vulpoi, A.; Pap, Z. Surface plasmon resonance or biocompatibility-Key properties for determining the applicability of noble metal nanoparticles. Materials 2017, 10, 836. [CrossRef]

10. Duan, X.; Li, Y. Physicochemical characteristics of nanoparticles affect circulation, biodistribution, cellular internalization, and trafficking. Small 2013, 9, 1521-1532. [CrossRef]

11. Sevenler, D.; Ünlü, N.L.; Ünlü, M.S. Nanoparticle Biosensing with Interferometric Reflectance Imaging. In Nanobiosensors and Nanobioanalyses; Springer: Berlin/Heidelberg, Germany, 2015; pp. 81-95.

12. Zhang, S.; Li, J.; Lykotrafitis, G.; Bao, G.; Suresh, S. Size-dependent endocytosis of nanoparticles. Adv. Mater. 2009, 21, 419-424. [CrossRef] [PubMed]

13. Liu, T.-M.; Yu, J.; Chang, C.A.; Chiou, A.; Chiang, H.K.; Chuang, Y.-C.; Wu, C.-H.; Hsu, C.-H.; Chen, P.-A.; Huang, C.-C. One-step shell polymerization of inorganic nanoparticles and their applications in SERS/nonlinear optical imaging, drug delivery and catalysis. Sci. Rep. 2014, 4, 5593. [CrossRef] [PubMed]

14. Yu, J.; Hsu, C.-H.; Huang, C.-C.; Chang, P.-Y. Development of therapeutic Au-methylene blue nanoparticles for targeted photodynamic therapy of cervical cancer cells. ACS Appl. Mater. Interfaces 2015, 7, 432-441. [CrossRef] [PubMed]

15. Tai, Y.-W.; Chiu, Y.-C.; Wu, P.-T.; Yu, J.; Chin, Y.-C.; Wu, S.-P.; Chuang, Y.-C.; Hsieh, H.-C.; Lai, P.-S.; Yu, H.-P. Degradable nir-ptt nanoagents with a potential cu@ cu2o@ polymer structure. ACS Appl. Mater. Interfaces 2018, 10, 5161-5174. [CrossRef] [PubMed]

16. Yang, H.-J.; He, S.-Y.; Chen, H.-L.; Tuan, H.-Y. Monodisperse copper nanocubes: Synthesis, self-assembly, and large-area dense-packed films. Chem. Mater. 2014, 26, 1785-1793. [CrossRef]

17. Huang, Y.; Lai, Y.; Shi, S.; Hao, S.; Wei, J.; Chen, X. Copper sulfide nanoparticles with phospholipid-PEG coating for in vivo near-infrared photothermal cancer therapy. Chem. Asian J. 2015, 10, 370-376. [CrossRef]

18. Hou, L.; Shan, X.; Hao, L.; Feng, Q.; Zhang, Z. Copper sulfide nanoparticle-based localized drug delivery system as an effective cancer synergistic treatment and theranostic platform. Acta Biomater. 2017, 54, 307-320. [CrossRef]

19. Feng, Q.; Zhang, W.; Li, Y.; Yang, X.; Hao, Y.; Zhang, H.; Li, W.; Hou, L.; Zhang, Z. An intelligent NIR-responsive chelate copper-based anticancer nanoplatform for synergistic tumor targeted chemo-phototherapy. Nanoscale 2017, 9, 15685-15695. [CrossRef]

20. Deng, D.; Cheng, Y.; Jin, Y.; Qi, T.; Xiao, F. Antioxidative effect of lactic acid-stabilized copper nanoparticles prepared in aqueous solution. J. Mater. Chem. 2012, 22, 23989-23995. [CrossRef] 
21. Yanina, I.Y.; Tuchin, V.V.; Navolokin, N.A.; Matveeva, O.V.; Bucharskaya, A.B.; Maslyakova, G.N.; Altshuler, G.B. Fat tissue histological study at indocyanine green-mediated photothermal/photodynamic treatment of the skin in vivo. J. Biomed. Opt. 2012, 17, 058002. [CrossRef]

22. Jaque, D.; Maestro, L.M.; del Rosal, B.; Haro-Gonzalez, P.; Benayas, A.; Plaza, J.; Rodriguez, E.M.; Sole, J.G. Nanoparticles for photothermal therapies. Nanoscale 2014, 6, 9494-9530. [CrossRef] [PubMed]

23. Shi, S.; Wen, X.; Li, T.; Wen, X.; Cao, Q.; Liu, X.; Liu, Y.; Pagel, M.D.; Li, C. Thermosensitive biodegradable copper sulfide nanoparticles for real-time multispectral optoacoustic tomography. ACS Appl. Bio Mater. 2019, 2, 3203-3211. [CrossRef]

24. De Solorzano, I.O.; Prieto, M.; Mendoza, G.; Alejo, T.; Irusta, S.; Sebastian, V.; Arruebo, M. Microfluidic synthesis and biological evaluation of photothermal biodegradable copper sulfide nanoparticles. ACS Appl. Mater. Interfaces 2016, 8, 21545-21554. [CrossRef] [PubMed]

25. Guo, L.; Panderi, I.; Yan, D.D.; Szulak, K.; Li, Y.; Chen, Y.-T.; Ma, H.; Niesen, D.B.; Seeram, N.; Ahmed, A. A comparative study of hollow copper sulfide nanoparticles and hollow gold nanospheres on degradability and toxicity. ACS Nano 2013, 7, 8780-8793. [CrossRef] [PubMed]

26. Conway, J.R.; Adeleye, A.S.; Gardea-Torresdey, J.; Keller, A.A. Aggregation, dissolution, and transformation of copper nanoparticles in natural waters. Environ. Sci. Technol. 2015, 49, 2749-2756. [CrossRef] [PubMed]

27. Chuang, Y.-T.; Cheng, T.-Y.; Kao, T.-L.; Liao, M.-Y. Hollow $\mathrm{Au}_{\mathrm{x}} \mathrm{Cu}_{1-\mathrm{x}}$ Alloy Nanoshells for Surface-Enhanced Raman-Based Tracking of Bladder Cancer Cells Followed by Triggerable Secretion Removal. ACS Appl. Nano Mater. 2020, 3, 7888-7898. [CrossRef]

28. Popescu, R.C.; Andronescu, E.; Grumezescu, A.M. In vivo evaluation of $\mathrm{Fe}_{3} \mathrm{O}_{4}$ nanoparticles. Rom. J. Morphol. Embryol. 2014, 55, 1013-1018.

29. Liao, M.-Y.; Lai, P.-S.; Yu, H.-P.; Lin, H.-P.; Huang, C.-C. Innovative ligand-assisted synthesis of NIR-activated iron oxide for cancer theranostics. Chem. Commun. 2012, 48, 5319-5321. [CrossRef]

30. Li, L.; Jiang, W.; Luo, K.; Song, H.; Lan, F.; Wu, Y.; Gu, Z. Superparamagnetic iron oxide nanoparticles as MRI contrast agents for non-invasive stem cell labeling and tracking. Theranostics 2013, 3, 595-615. [CrossRef]

31. Kao, C.-W.; Wu, P.-T.; Liao, M.-Y.; Chung, I.-J.; Yang, K.-C.; Tseng, W.-Y.I.; Yu, J. Magnetic nanoparticles conjugated with peptides derived from monocyte chemoattractant protein-1 as a tool for targeting atherosclerosis. Pharmaceutics 2018, 10, 62. [CrossRef]

32. Freund, B.; Tromsdorf, U.I.; Bruns, O.T.; Heine, M.; Giemsa, A.; Bartelt, A.; Salmen, S.C.; Raabe, N.; Heeren, J.; Ittrich, $\mathrm{H}$. A simple and widely applicable method to 59Fe-radiolabel monodisperse superparamagnetic iron oxide nanoparticles for in vivo quantification studies. ACS Nano 2012, 6, 7318-7325. [CrossRef] [PubMed]

33. Dadfar, S.M.; Camozzi, D.; Darguzyte, M.; Roemhild, K.; Varvarà, P.; Metselaar, J.; Banala, S.; Straub, M.; Güvener, N.; Engelmann, U. Size-isolation of superparamagnetic iron oxide nanoparticles improves MRI, MPI and hyperthermia performance. J. Nanobiotechnol. 2020, 18, 1-13. [CrossRef] [PubMed]

34. Liao, M.Y.; Wu, C.H.; Lai, P.S.; Yu, J.; Lin, H.P.; Liu, T.M.; Huang, C.C. Surface State Mediated NIR Two-Photon Fluorescence of Iron Oxides for Nonlinear Optical Microscopy. Adv. Funct. Mater. 2013, 23, 2044-2051. [CrossRef]

35. Yao, Y.; Chen, H.; Qin, J.; Wu, G.; Lian, C.; Zhang, J.; Wang, S. Iron encapsulated in boron and nitrogen codoped carbon nanotubes as synergistic catalysts for Fenton-like reaction. Water Res. 2016, 101, 281-291. [CrossRef]

36. Yang, B.; Chen, Y.; Shi, J. Reactive oxygen species (ROS)-based nanomedicine. Chem. Rev. 2019, 119, 4881-4985. [CrossRef]

37. Winterbourn, C.C. Toxicity of iron and hydrogen peroxide: The Fenton reaction. Toxicol. Lett. 1995, 82, 969-974. [CrossRef]

38. Kim, J.; Cho, H.R.; Jeon, H.; Kim, D.; Song, C.; Lee, N.; Choi, S.H.; Hyeon, T. Continuous $\mathrm{O}_{2}$-evolving $\mathrm{MnFe}_{2} \mathrm{O}_{4}$ nanoparticle-anchored mesoporous silica nanoparticles for efficient photodynamic therapy in hypoxic cancer. J. Am. Chem. Soc. 2017, 139, 10992-10995. [CrossRef]

39. Hu, P.; Wu, T.; Fan, W.; Chen, L.; Liu, Y.; Ni, D.; Bu, W.; Shi, J. Near infrared-assisted Fenton reaction for tumor-specific and mitochondrial DNA-targeted photochemotherapy. Biomaterials 2017, 141, 86-95. [CrossRef]

40. Lopez-Lázaro, M. Dual role of hydrogen peroxide in cancer: Possible relevance to cancer chemoprevention and therapy. Cancer Lett. 2007, 252, 1-8. [CrossRef] 
41. Huo, M.; Wang, L.; Chen, Y.; Shi, J. Tumor-selective catalytic nanomedicine by nanocatalyst delivery. Nat. Commun. 2017, 8, 357. [CrossRef]

42. Mazuel, F.; Espinosa, A.; Luciani, N.; Reffay, M.; le Borgne, R.; Motte, L.; Desboeufs, K.; Michel, A.; Pellegrino, T.; Lalatonne, Y. Massive intracellular biodegradation of iron oxide nanoparticles evidenced magnetically at single-endosome and tissue levels. ACS Nano 2016, 10, 7627-7638. [CrossRef] [PubMed]

43. Liu, Y.; Zhen, W.; Jin, L.; Zhang, S.; Sun, G.; Zhang, T.; Xu, X.; Song, S.; Wang, Y.; Liu, J. All-in-one theranostic nanoagent with enhanced reactive oxygen species generation and modulating tumor microenvironment ability for effective tumor eradication. ACS Nano 2018, 12, 4886-4893. [CrossRef] [PubMed]

44. Wang, D.; Zhang, Y.; Guo, Q. Sub-10 nm Cu5FeS4 cube for magnetic resonance imaging-guided photothermal therapy of cancer. Int. J. Nanomed. 2018, 13, 7987. [CrossRef] [PubMed]

45. Ding, B.; Yu, C.; Li, C.; Deng, X.; Ding, J.; Cheng, Z.; Xing, B.; Lin, J. cis-Platinum pro-drug-attached CuFeS 2 nanoplates for in vivo photothermal/photoacoustic imaging and chemotherapy/photothermal therapy of cancer. Nanoscale 2017, 9, 16937-16949. [CrossRef] [PubMed]

46. Lin, K.; Cao, Y.; Zheng, D.; Li, Q.; Liu, H.; Yu, P.; Li, J.; Xue, Y.; Wu, M. Facile phase transfer of hydrophobic Fe 3 O 4@ Cu 2-x S nanoparticles by red blood cell membrane for MRI and phototherapy in the second near-infrared window. J. Mater. Chem. B 2020, 8, 1202-1211. [CrossRef]

47. Liu, T.-M.; Conde, J.; Lipiński, T.; Bednarkiewicz, A.; Huang, C.-C. Smart NIR linear and nonlinear optical nanomaterials for cancer theranostics: Prospects in photomedicine. Prog. Mater. Sci. 2017, 88, 89-135. [CrossRef]

48. Zhao, Z.; Huang, Y.; Shi, S.; Tang, S.; Li, D.; Chen, X. Cancer therapy improvement with mesoporous silica nanoparticles combining photodynamic and photothermal therapy. Nanotechnology 2014, 25, 285701. [CrossRef]

49. Zeng, W.; Zhang, H.; Deng, Y.; Jiang, A.; Bao, X.; Guo, M.; Li, Z.; Wu, M.; Ji, X.; Zeng, X. Dual-response oxygen-generating $\mathrm{MnO}_{2}$ nanoparticles with polydopamine modification for combined photothermal-photodynamic therapy. Chem. Eng. J. 2020, 389, 124494. [CrossRef]

50. Wang, K.; Zhang, Y.; Wang, J.; Yuan, A.; Sun, M.; Wu, J.; Hu, Y. Self-assembled IR780-loaded transferrin nanoparticles as an imaging, targeting and PDT/PTT agent for cancer therapy. Sci. Rep. 2016, 6, 27421. [CrossRef]

51. Khdair, A.; Chen, D.; Patil, Y.; Ma, L.; Dou, Q.P.; Shekhar, M.P.; Panyam, J. Nanoparticle-mediated combination chemotherapy and photodynamic therapy overcomes tumor drug resistance. J. Control. Release 2010, 141, 137-144. [CrossRef]

52. Hah, H.J.; Kim, G.; Lee, Y.E.K.; Orringer, D.A.; Sagher, O.; Philbert, M.A.; Kopelman, R. Methylene blue-conjugated hydrogel nanoparticles and tumor-cell targeted photodynamic therapy. Macromol. Biosci. 2011, 11, 90-99. [CrossRef] [PubMed]

53. Wu, P.-T.; Lin, C.-L.; Lin, C.-W.; Chang, N.-C.; Tsai, W.-B.; Yu, J. Methylene-blue-encapsulated liposomes as photodynamic therapy nano agents for breast cancer cells. Nanomaterials 2019, 9, 14. [CrossRef] [PubMed]

54. Seo, S.-H.; Kim, B.-M.; Joe, A.; Han, H.-W.; Chen, X.; Cheng, Z.; Jang, E.-S. NIR-light-induced surface-enhanced Raman scattering for detection and photothermal/photodynamic therapy of cancer cells using methylene blue-embedded gold nanorod@ $\mathrm{SiO}_{2}$ nanocomposites. Biomaterials 2014, 35, 3309-3318. [CrossRef] [PubMed]

55. Hosseinzadeh, R.; Khorsandi, K. Photodynamic effect of Zirconium phosphate biocompatible nano-bilayers containing methylene blue on cancer and normal cells. Sci. Rep. 2019, 9, 1-13. [CrossRef] [PubMed]

56. Ramyadevi, J.; Jeyasubramanian, K.; Marikani, A.; Rajakumar, G.; Rahuman, A.A.; Santhoshkumar, T.; Kirthi, A.V.; Jayaseelan, C.; Marimuthu, S. Copper nanoparticles synthesized by polyol process used to control hematophagous parasites. Parasitol. Res. 2011, 109, 1403-1415. [CrossRef]

57. Henglein, A. Formation and absorption spectrum of copper nanoparticles from the radiolytic reduction of $\mathrm{Cu}(\mathrm{CN})_{2}$. J. Phys. Chem. B 2000, 104, 1206-1211. [CrossRef]

58. Dang, T.M.D.; Le, T.T.T.; Fribourg-Blanc, E.; Dang, M.C. Synthesis and optical properties of copper nanoparticles prepared by a chemical reduction method. Adv. Nat. Sci. Nanosci. Nanotechnol. 2011, 2, 015009. [CrossRef]

59. Zhu, M.; Meng, D.; Wang, C.; Diao, G. Facile fabrication of hierarchically porous $\mathrm{CuFe}_{2} \mathrm{O}_{4}$ nanospheres with enhanced capacitance property. ACS Appl. Mater. Interfaces 2013, 5, 6030-6037. [CrossRef] 
60. Xiao, J.; Fang, X.; Yang, S.; He, H.; Sun, C. Microwave-assisted heterogeneous catalytic oxidation of high-concentration Reactive yellow 3 with $\mathrm{CuFe}_{2} \mathrm{O}_{4} / \mathrm{PAC}$. J. Chem. Technol. Biotechnol. 2015, 90, 1861-1868. [CrossRef]

61. Ma, X.; Gong, A.; Chen, B.; Zheng, J.; Chen, T.; Shen, Z.; Wu, A. Exploring a new SPION-based MRI contrast agent with excellent water-dispersibility, high specificity to cancer cells and strong MR imaging efficacy. Colloids Surf. B Biointerfaces 2015, 126, 44-49. [CrossRef]

62. Carvalho, A.; Martins, M.; Corvo, M.; Feio, G. Enhanced contrast efficiency in MRI by PEGylated magnetoliposomes loaded with PEGylated SPION: Effect of SPION coating and micro-environment. Mater. Sci. Eng. C 2014, 43, 521-526. [CrossRef] [PubMed]

63. Wang, N.; Zheng, T.; Jiang, J.; Wang, P. Cu (II)-Fe (II)- $\mathrm{H}_{2} \mathrm{O}_{2}$ oxidative removal of 3-nitroaniline in water under microwave irradiation. Chem. Eng. J. 2015, 260, 386-392. [CrossRef]

64. Urbański, N.K.; Beresewicz, A. Generation of* $\mathrm{OH}$ initiated by interaction of $\mathrm{Fe} 2+$ and $\mathrm{Cu}+$ with dioxygen; Comparison with the Fenton chemistry. Acta Biochim. Pol. 2000, 47, 951-962. [CrossRef]

65. Lu, H.; Zhu, Z.; Zhang, H.; Zhu, J.; Qiu, Y.; Zhu, L.; Küppers, S. Fenton-like catalysis and oxidation/adsorption performances of acetaminophen and arsenic pollutants in water on a multimetal Cu-Zn-Fe-LDH. ACS Appl. Mater. Interfaces 2016, 8, 25343-25352. [CrossRef] [PubMed]

66. Huang, C.-C.; Chang, P.-Y.; Liu, C.-L.; Xu, J.-P.; Wu, S.-P.; Kuo, W.-C. New insight on optical and magnetic Fe $3 \mathrm{O} 4$ nanoclusters promising for near infrared theranostic applications. Nanoscale 2015, 7, 12689-12697. [CrossRef]

67. Pandey, N.K.; Chudal, L.; Phan, J.; Lin, L.; Johnson, O.; Xing, M.; Liu, J.P.; Li, H.; Huang, X.; Shu, Y. A facile method for the synthesis of copper-cysteamine nanoparticles and study of ROS production for cancer treatment. J. Mater. Chem. B 2019, 7, 6630-6642. [CrossRef]

68. Thanh, N.T.; Maclean, N.; Mahiddine, S. Mechanisms of nucleation and growth of nanoparticles in solution. Chem. Rev. 2014, 114, 7610-7630. [CrossRef]

69. Salavati-Niasari, M.; Mahmoudi, T.; Sabet, M.; Hosseinpour-Mashkani, S.M.; Soofivand, F.; Tavakoli, F. Synthesis and characterization of copper ferrite nanocrystals via coprecipitation. J. Clust. Sci. 2012, 23, 1003-1010. [CrossRef]

70. Wang, X.; Zhong, X.; Liu, Z.; Cheng, L. Recent progress of chemodynamic therapy-induced combination cancer therapy. Nano Today 2020, 35, 100946. [CrossRef]

71. Tang, Z.; Liu, Y.; He, M.; Bu, W. Chemodynamic therapy: Tumour microenvironment-mediated Fenton and Fenton-like reactions. Angew. Chem. Int. Ed. 2019, 58, 946-956. [CrossRef]

72. Xiao, J.; Zhang, G.; Xu, R.; Chen, H.; Wang, H.; Tian, G.; Wang, B.; Yang, C.; Bai, G.; Zhang, Z. A pH-responsive platform combining chemodynamic therapy with limotherapy for simultaneous bioimaging and synergistic cancer therapy. Biomaterials 2019, 216, 119254. [CrossRef] [PubMed]

73. Choi, S.S.; Lee, H.K.; Chae, H.S. Synergistic in vitro photodynamic antimicrobial activity of methylene blue and chitosan against Helicobacter pylori 26695. Photodiagn. Photodyn. Ther. 2014, 11, 526-532. [CrossRef] [PubMed]

74. Lu, Y.; Jiao, R.; Chen, X.; Zhong, J.; Ji, J.; Shen, P. Methylene blue-mediated photodynamic therapy induces mitochondria-dependent apoptosis in HeLa Cell. J. Cell. Biochem. 2008, 105, 1451-1460. [CrossRef] [PubMed]

75. Wang, J.; Liu, C.; Li, J.; Luo, R.; Hu, X.; Sun, X.; Shen, J.; Han, W.; Wang, L. In-situ incorporation of iron-copper bimetallic particles in electrospun carbon nanofibers as an efficient Fenton catalyst. Appl. Catal. B Environ. 2017, 207, 316-325. [CrossRef]

76. Wang, Y.; Zhao, H.; Zhao, G. Iron-copper bimetallic nanoparticles embedded within ordered mesoporous carbon as effective and stable heterogeneous Fenton catalyst for the degradation of organic contaminants. Appl. Catal. B Environ. 2015, 164, 396-406. [CrossRef]

77. Cheng, L.-C.; Huang, J.-H.; Chen, H.M.; Lai, T.-C.; Yang, K.-Y.; Liu, R.-S.; Hsiao, M.; Chen, C.-H.; Her, L.-J.; Tsai, D.P. Seedless, silver-induced synthesis of star-shaped gold/silver bimetallic nanoparticles as high efficiency photothermal therapy reagent. J. Mater. Chem. 2012, 22, 2244-2253. [CrossRef]

78. Mishra, S.K.; Kannan, S. A bimetallic silver-neodymium theranostic nanoparticle with multimodal NIR/MRI/CT imaging and combined chemo-photothermal therapy. Inorg. Chem. 2017, 56, 12054-12066. [CrossRef]

79. Skrabalak, S.E.; Chen, J.; Sun, Y.; Lu, X.; Au, L.; Cobley, C.M.; Xia, Y. Gold nanocages: Synthesis, properties, and applications. Acc. Chem. Res. 2008, 41, 1587-1595. [CrossRef] 
80. Srinoi, P.; Chen, Y.-T.; Vittur, V.; Marquez, M.D.; Lee, T.R. Bimetallic nanoparticles: Enhanced magnetic and optical properties for emerging biological applications. Appl. Sci. 2018, 8, 1106. [CrossRef]

81. Chernikova, E.; Terpugova, P.; Bui, C.; Charleux, B. Effect of comonomer composition on the controlled free-radical copolymerization of styrene and maleic anhydride by reversible addition-fragmentation chain transfer (RAFT). Polymer 2003, 44, 4101-4107. [CrossRef]

82. Henry, S.M.; El-Sayed, M.E.; Pirie, C.M.; Hoffman, A.S.; Stayton, P.S. pH-responsive poly (styrene-alt-maleic anhydride) alkylamide copolymers for intracellular drug delivery. Biomacromolecules 2006, 7, 2407-2414. [CrossRef] [PubMed]

83. Larson, N.; Greish, K.; Bauer, H.; Maeda, H.; Ghandehari, H. Synthesis and evaluation of poly (styrene-co-maleic acid) micellar nanocarriers for the delivery of tanespimycin. Int. J. Pharm. 2011, 420, 111-117. [CrossRef] [PubMed]

84. Rodriguez, V.B.; Henry, S.M.; Hoffman, A.S.; Stayton, P.S.; Li, X.; Pun, S.H. Encapsulation and stabilization of indocyanine green within poly (styrene-alt-maleic anhydride) block-poly (styrene) micelles for near-infrared imaging. J. Biomed. Opt. 2008, 13, 014025. [CrossRef] [PubMed]

Publisher's Note: MDPI stays neutral with regard to jurisdictional claims in published maps and institutional affiliations.

(C) 2020 by the authors. Licensee MDPI, Basel, Switzerland. This article is an open access article distributed under the terms and conditions of the Creative Commons Attribution (CC BY) license (http://creativecommons.org/licenses/by/4.0/). 